\title{
Early Experience with Targeted Therapy and Dendritic Cell Vaccine in Metastatic Renal Cell Carcinoma after Nephrectomy
}

\author{
Marcos F. Dall'Oglio, Juliana M. Sousa-Canavez, Fabio Y. Tanno, Bruno C. Tiseo, Alexandre \\ Crippa, Sabrina T. dos Reis, Katia R. M. Leite, Miguel Srougi
}

Division of Urology (MFDO, FYT, BCT, STR, KRML, MS), Medical School, University of Sao Paulo, Sao Paulo, Brazil, Genoa Biotechnology (JMSC), Sao Paulo, Brazil and Institute of Cancer of Sao Paulo (AC), ICESP, Sao Paulo, Brazil

\begin{abstract}
Purpose: Metastatic renal cell carcinoma (RCC) is one of the most treatment-resistant malignancies and nephrectomy, isolated or combined with systemic chemotherapy typically has limited or no effectiveness. We report our initial results in patients treated with the association of molecular targeted therapy, nephrectomy, and hybrid dendritic-tumor cell (DC) vaccine.

Materials and Methods: Two male patients diagnosed with metastatic RCC were selected for the study. They were treated with the triple strategy, in which sunitinib (50 mg per day) was given for 4 weeks, followed by radical nephrectomy after two weeks. DC vaccine was initiated immediately after surgery and repeated monthly. Sunitinib was restarted daily after 2 to 3 weeks of surgery with a 7-day interval every 4 weeks.

Results: Both patients had complete adherence to the proposed treatment with DC vaccine therapy combined with sunitinib. Follow-up in these patients at 9 and 10 months demonstrated a stable disease in both, as shown by imaging and clinical findings, with no further treatment required.

Conclusion: The immune response obtained with DC vaccine combined with the antiangiogenic effect of sunitinib and the potential benefits of cytoreductive nephrectomy in advanced disease could represent a new option in the treatment of metastatic RCC. Further prospective trials are needed not only to elucidate the ideal dosing and schedule, but also to better define the proof-of-concept proposed in this report and its role in clinical practice.
\end{abstract}

Key words: renal cell carcinoma, dendritic cells, neoplasm metastasis

Int Braz, J Urol. 2011; 37: 180-6

\section{INTRODUCTION}

Renal cell carcinoma (RCC), the most common type of kidney cancer, is commonly asymptomatic in its early stages. Consequently, $25-30 \%$ of patients are diagnosed with metastatic disease at initial presentation. The incidence of RCC has grown at a rate of $3.7 \%$ in recent years (1). The etiology of RCC is still widely unknown and the disease primarily affects men and women in the fifth and sixth decades of life (2). It is characterized by a lack of early warning signs and diverse clinical manifestations. RCC has historically been a difficult malignancy to diagnose and also to treat, because it remains clinically occult for most of its course. It is often diagnosed incidentally following radiologic studies. In advanced stages, treatment results are extremely poor, with response rates for treated patients remaining between $5 \%$ to $10 \%$ and overall median survival of less than one year (3). The US National Cancer Institute has estimated 
approximately 15.7 years of life lost per-person dying (4). The cytoreductive surgery (nephrectomy) and/or systemic treatment with cytotoxic chemotherapy typically have limited or no effectiveness (5).

Recently, less-toxic molecular targeted therapies have been the subject of clinical trials of advanced RCC, including sorafenib and sunitinib, which have shown survival benefits for patients with metastatic RCC. This strategy has become an important therapy option with promising results, such as extending life and bringing quality of life to these patients (6).

Dendritic cells (DC) are potent antigen-presenting cells and effective initiators of an invasive response (7). The recent development of DC in vitro has opened new possibilities for cancer therapy. Kugler et al. were the first to demonstrate the possibility of DC to become a tumor vaccine for metastatic RCC (8). More recently, significant responses were reported in this disease stage with vaccines based on DC hybridized with cells from the tumor itself $(9,10)$. However, trials evaluating vaccine-based therapies are still awaited. The use of vaccines in cancer, nonetheless, will initially only be possible in a combined approach, in which current strategies, surgery as a cytoreductive enhancer, and novel agents are included (11).

Since the mechanism by which DC therapy strongly stimulates the patient's immunologic system greatly differs from that of the targeted-drug by anti-angiogenic effect, we attempted to assess the possible added or synergic combination of those two therapies.

We report on our initial experience with patients treated with a multi-modality approach, in which we combined a molecular targeted drug, cytoreductive nephrectomy, and hybrid DC vaccine.

\section{MATERIALS AND METHODS}

Two male patients presenting renal masses and systemic metastasis at first assessment were included in this analysis (Table-1).

By the time of diagnosis, the patients already had several distant metastatic masses and bulky renal tumors on imaging studies (Figure-1). The treatment was initiated with sunitinib (50 mg per day) before surgery for 30 days. After two weeks, patients under- went radical nephrectomy. DC vaccine was administered just after the surgery and monthly thereafter. The use of sunitinib was restarted after 2 to 3 weeks of surgery (Table-1).

The DC vaccine was prepared and obtained as previously described $(9,10)$. In summary, peripheral blood mononuclear cells were collected from healthy unrelated volunteers through apheresis, after informed consent of donors. Mononuclear cells were separated further with a density gradient, resuspended, and seeded in culture flasks in RPMI 1640 culture medium. Then, flasks were incubated at $37^{\circ} \mathrm{C}$ for a period of $4 \mathrm{~h}$, when nonadherent cells were removed, and the RPMI medium was replaced by a serum-free medium containing GM-CSF (50 ng/mL; R\&D, Minneapolis, MN, USA) and interleukin $4(50 \mathrm{ng} / \mathrm{mL}$; R\&D, Minneapolis, $\mathrm{MN}$, USA). After 5 days in culture, TNF-a $(50 \mathrm{ng} / \mathrm{mL} ; \mathrm{R} \& \mathrm{D}$, Minneapolis, MN, USA) was added to the cultures for DC activation. After 2 further days in culture, cells were harvested and used for the generation of the dendritic-tumor hybrid vaccine. At the last day of DC cultures, DCs were harvested, washed, and resuspended in a sterile $5 \%$ glucose solution at a concentration of 1107 cells $/ \mathrm{mL}$. Tumor cells were thawed, washed, and also resuspended in a sterile $5 \%$ glucose solution at a concentration of 1107 cells $/ \mathrm{mL}$. These two cell suspensions were mixed at equal volumes, and cells were fused by an electric pulse. Shortly after fusion, all cells stained with trypan blue. The hybrid cell preparation was centrifuged, resuspended in 1-2 $\mathrm{mL}$ of sterile phosphate-buffered saline ( $\mathrm{pH}$ 7.2) and, after irradiation (200 Gy), injected in the patients. At this moment, cell viability ranged from 60 to $80 \%$ of the initial tumor cell viability. Vaccine injections were intradermic.

\section{RESULTS}

In both patients, we observed stabilization of the lesions after sunitinib was given. After radical nephrectomy, no surgical complications were observed and complete wound healing occurred.

Patient 1 - Sixty days after surgery, we observed a major decrease of pleural effusion and stabilization of lung lesions (Figures 2 and 3). A 120-day control test repeated those findings and showed a reduction of the right lung and pleural le- 
Table 1 - Patient's characteristics, management and follow-up.

\begin{tabular}{|c|c|c|}
\hline & Patient 1 & Patient 2 \\
\hline Age (years) & 55 & 62 \\
\hline Initial symptom & 6 months with cough & Cervical mass and loss of weight \\
\hline Metastasis location & $\begin{array}{c}\text { Pulmonary, mediastinal, and pleural } \\
\text { effusion. }\end{array}$ & Pulmonary, cervical and supraclavicular \\
\hline Comorbities & Hypertension and diabetes mellitus type 2 & - \\
\hline $\begin{array}{l}\text { Time using sunitinib } \\
\text { before surgery }\end{array}$ & 30 days & 30 days \\
\hline Surgical treatment & $\begin{array}{c}\text { Videolaparoscopic radical left } \\
\text { nephrectomy }\end{array}$ & Open radical left nephrectomy \\
\hline Pathologic examination & $\begin{array}{l}\text { Clear cell RCC, Fuhrman IV, positive } \\
\text { for microvascular invasion, lymph node } \\
\text { metastasis, tumor size: } 7 \mathrm{~cm}\end{array}$ & $\begin{array}{c}\text { Clear cell RCC, Fuhrman IV, positive for } \\
\text { microvascular invasion, lymph node metas- } \\
\text { tasis, tumor size: } 12 \mathrm{~cm}\end{array}$ \\
\hline Vaccine doses & 7 & 8 \\
\hline $\begin{array}{l}\text { Restart delay in the use of } \\
\text { sunitinib after surgery }\end{array}$ & 21 days & 14 days \\
\hline $\begin{array}{l}\text { Complications - surgical } \\
\text { wound }\end{array}$ & - & - \\
\hline Imaging & $\begin{array}{l}\text { Partial regression / Pleural efusion } \\
\text { regression }\end{array}$ & Partial regression \\
\hline Side-effects & Hand-foot syndrome & Weakness / diarrhea \\
\hline Time of follow-up & 9 months & 10 months \\
\hline
\end{tabular}

$R C C=$ renal cell carcinoma.

sions. Complete disappearance of the small left lung lesions was observed. The patient continued clinical follow-up with stabilized lesions until the last visit, with no new symptoms.

Patient 2 - We observed a partial regression of the lung lesions as well as a significant and continuous decrease of the cervical mass, as shown in Figure-4.

Until their last follow-up, both patients were kept on treatment with DC vaccine therapy and the use of sunitinib daily, with a 7-day interval every 4 weeks, with an apparent stable disease.

\section{COMMENTS}

Futures strategies for the treatment of metastatic RCC will try to aggregate several drug therapies to act on different pathways.
This treatment with DC has the advantage of presenting minimum adverse events, providing a better quality of life for patients, in contrast to the usual therapy with cytokines that, in spite of presenting objective responses, is associated with serious side effects, which can lead to poor quality of life or even death. DC initiates an immune response and, nowadays, we can generate these cells in the laboratory, providing a cancer therapy (7). Kugler et al. have published good results with stabilization of renal metastatic lesions after the association of surgical treatment with DC vaccines for metastatic RCC (8). A study with DC vaccine alone, published by Barbuto et al. (10), for the treatment of metastatic RCC showed stabilization of the disease in $71 \%$ of the patients in median 6.7 months of follow-up (5-21 months).

The safety and effectiveness of these targeted drugs are well documented in current literature with metastatic RCC stabilization for about 5.5 to 


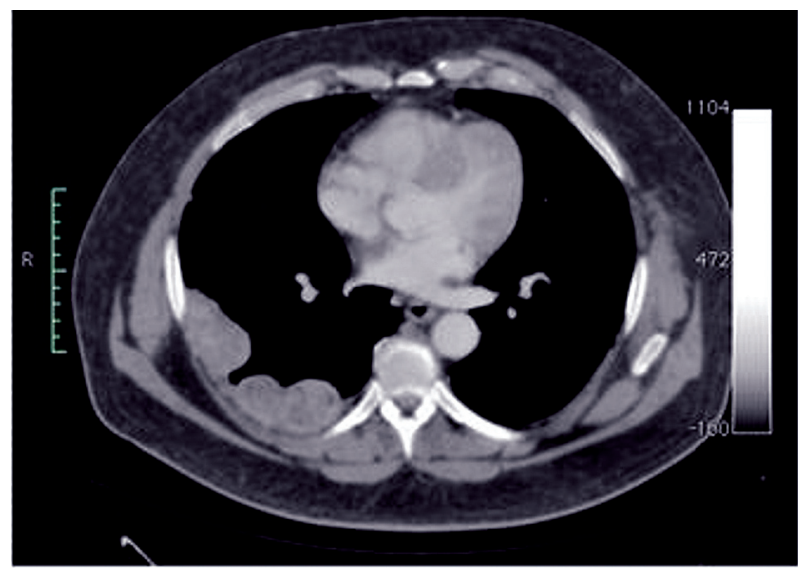

Figure 1 - Patient 1: Thoracic CT scan showing metastatic nodules.

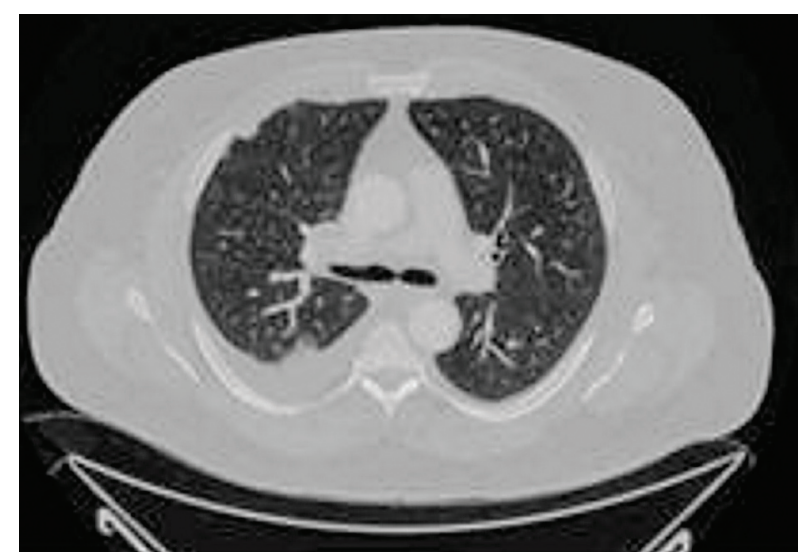

Figure 2-Patient 1: CT scan showing pleural effusion among pleural metastasis.
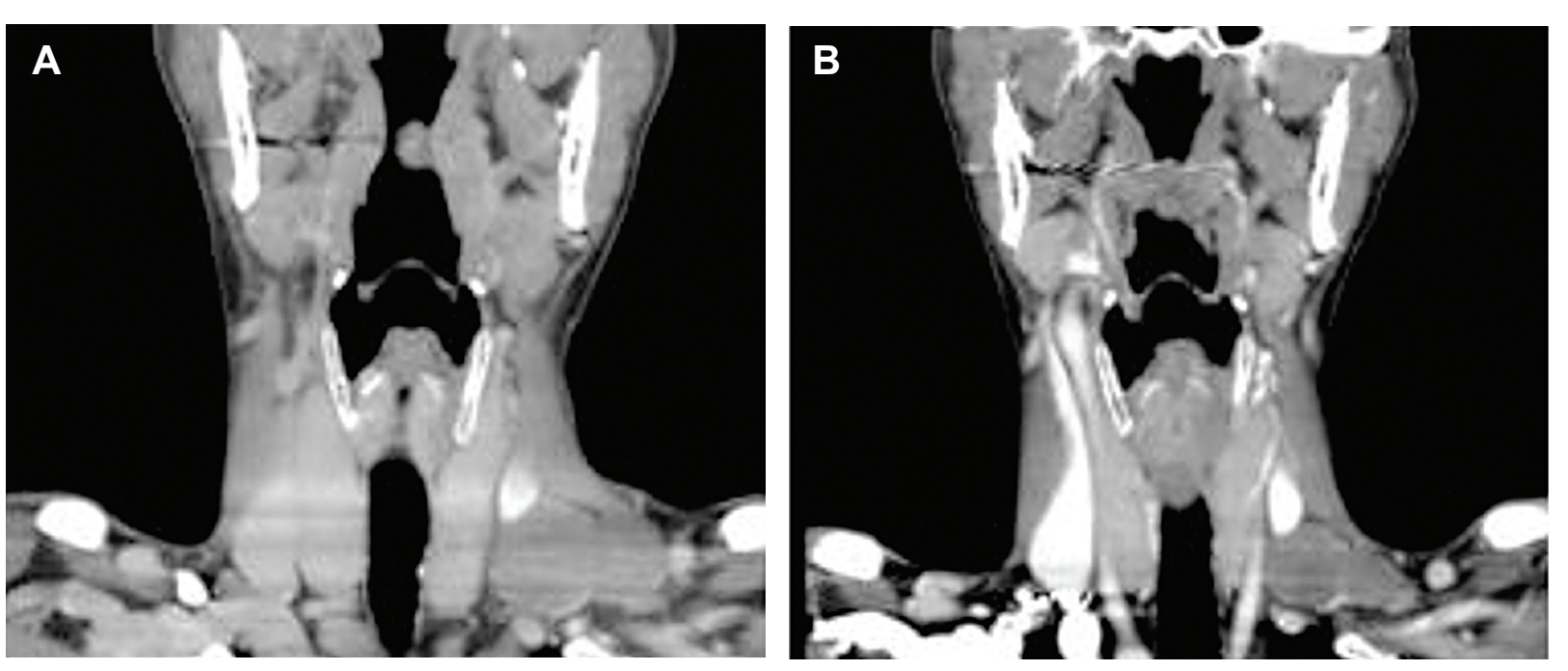

Figure 4-A) Patient 2: Coronal CT scan showing a cervical node metastasis. B) Coronal CT scan presenting clear regression of cervical mass after treatment.
11 months with sorafenib (12) and sunitinib (13), respectively. The use of DC vaccine has also shown promising results in some reported cases in the literature (9).

The use of DC vaccine in association with targeted drugs is controversial and was first assumed that it could be used with sunitinib alone, (14) although it could also be used with sorafenib as demonstrated by Alfaro et al. (15).

The use of targeted therapy with DC vaccine after nephrectomy in metastatic RCC disease has not yet been published. It shows a possible synergy by those two approaches, leading to a more promising

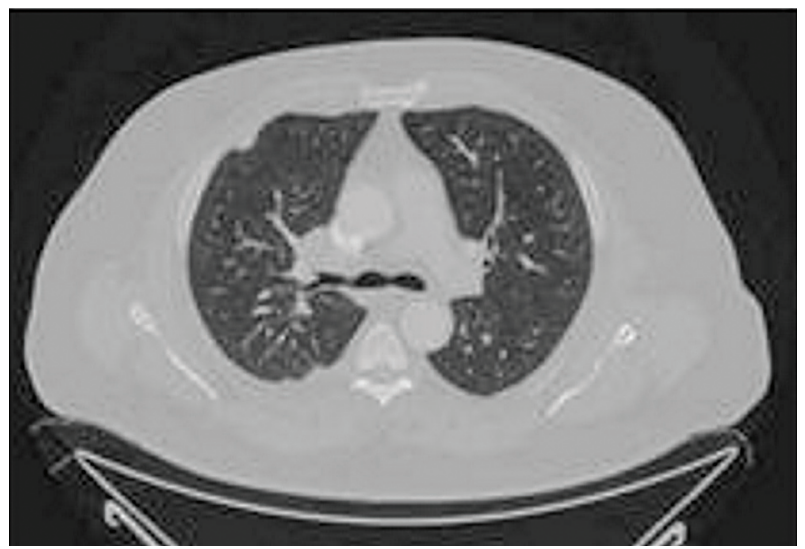

Figure 3-Patient 1: CT scan with regression of the pleural effusion without thoracocentesis.

cervical mass after treatment. 
anti-tumoral control using two distinct mechanisms of action, in combination with a cytoreductive surgery.

Even though these multi-drug therapies for metastatic RCC disease were a good and reasonable possibility, the combination of sunitinib with sorafenib failed to prove its effectiveness (16). Despite important progress in metastatic RCC after the introduction of targeted therapy, clinically significant benefit is limited. Several issues still remain unclear, lacking proper prospective clinical trials for an evidence-based guideline (17).

Sunitinib is a tirosine kinase inhibitor with double action: antiproliferative and antiangiogenic, (12) Bevacizumab is another inhibitor of angiogenesis (18) and tensirolimus a specific inhibitor of the mammalian target of rapamycin kinase (19). Apparently, any of these drugs could be used in association with DC vaccine based on the Alfaro et al. study (15).

Cytoreductive nephrectomy in metastatic $\mathrm{RCC}$ has shown benefits in a significant number of patients improving disease-specific survival (20). These newly developed targeted-drug therapies may bring new expectations for these patients with a poor life expectancy.

Until now, at ten months follow-up, we could observe a regression of metastatic lesions and stabilization of the disease in imaging tests with DC vaccine combined to a targeted-drug therapy. This may represent a new and promising strategy of treatment for clinical use, since median life expectancy for metastatic RCC using sunitinib alone or interferon was 5.3 and 4 months, respectively, as reported by Motzer et al. $(21,22)$. Novel insights into immunology and biology of the tumor have accelerated research on vaccines, which demonstrated significant efficacy as antitumoral agents (23).

The immune response obtained with DC vaccine associated with the antiangiogenic effect of sunitinib appear to present a new horizon in the therapy of metastatic RCC pointing towards a new option for treatment of a potential lethal disease as demonstrated in this small series of cases.

\section{CONFLICT OF INTEREST}

None declared.

\section{REFERENCES}

1. Jemal A, Siegel R, Ward E, Hao Y, Xu J, Thun MJ: Cancer statistics, 2009. CA Cancer J Clin. 2009; 59: 225-49.

2. Murai M, Oya M: Renal cell carcinoma: etiology, incidence and epidemiology. Curr Opin Urol. 2004; 14: 229-33.

3. Lam JS, Leppert JT, Belldegrun AS, Figlin RA: Novel approaches in the therapy of metastatic renal cell carcinoma. World J Urol. 2005; 23: 202-12.

4. Ries LAG, Melbert D, Krapcho M, Mariotto A, Miller BA, Feuer EJ, et al.: Editors. SEER Cancer Statistics Review, 1975-2004. National Cancer Institute. Bethesda, MD, 2007. [Cited nov 2006]. Available at: http://seer.cancer.gov/csr/1975 2004.

5. Motzer RJ, Russo P: Systemic therapy for renal cell carcinoma. J Urol. 2000; 163: 408-17.

6. Rini BI, Campbell SC, Escudier B: Renal cell carcinoma. Lancet. 2009; 373: 1119-32.

7. Banchereau J, Steinman RM: Dendritic cells and the control of immunity. Nature. 1998; 392: 245-52.

8. Kugler A, Stuhler G, Walden P, Zöller G, Zobywalski A, Brossart P, et al.: Regression of human metastatic renal cell carcinoma after vaccination with tumor cell-dendritic cell hybrids. Nat Med. 2000; 6: 332-6. Retraction in: Kugler A, Stuhler G, Walden P, Zöller G, Zobywalski A, Brossart P, Trefzer U, Ullrich S, Müller CA, Becker V, Gross AJ, Hemmerlein B, Kanz L, Müller GA, Ringert RH. Nat Med. 2003; 9: 1221.

9. Dall'Oglio M, Srougi M, Barbuto JA: Complete response of metastatic renal cancer with dendritic cell vaccine. Int Braz J Urol. 2003; 29: 517-9.

10. Barbuto JA, Ensina LF, Neves AR, Bergami-Santos P, Leite KR, Marques R, et al.: Dendritic cell-tumor cell hybrid vaccination for metastatic cancer. Cancer Immunol Immunother. 2004; 53: 1111-8.

11. de Reijke TM, Bellmunt J, van Poppel H, Marreaud S, Aapro M: EORTC-GU group expert opinion on metastatic renal cell cancer. Eur J Cancer. 2009; 45: 765-73.

12. Hipp MM, Hilf N, Walter S, Werth D, Brauer KM, Radsak MP, et al.: Sorafenib, but not sunitinib, affects function of dendritic cells and induction of primary immune responses. Blood. 2008; 111: 5610-20.

13. Escudier B, Eisen T, Stadler WM, Szczylik C, Oudard $\mathrm{S}$, Siebels M, et al.: Sorafenib in advanced clear-cell renal-cell carcinoma. N Engl J Med. 2007; 356: 12534. Erratum in: N Engl J Med. 2007; 357: 203.

14. Motzer RJ, Hutson TE, Tomczak P, Michaelson MD, Bukowski RM, Rixe O, et al.: Sunitinib versus inter- 


\section{A New Therapeutic to Metastatic Renal Cell Carcinoma}

feron alfa in metastatic renal-cell carcinoma. N Engl J Med. 2007; 356: 115-24.

15. Alfaro C, Suarez N, Gonzalez A, Solano S, Erro L, Dubrot J, et al.: Influence of bevacizumab, sunitinib and sorafenib as single agents or in combination on the inhibitory effects of VEGF on human dendritic cell differentiation from monocytes. Br J Cancer. 2009; 100: 1111-9.

16. Vogelzang NJ: Treatment options in metastatic renal carcinoma: an embarrassment of riches. J Clin Oncol. 2006; 24: 1-3.

17. Heldwein FL, Escudier B, Smyth G, Souto CA, Vallancien G: Metastatic renal cell carcinoma management. Int Braz J Urol. 2009; 35: 256-70.

18. Yang JC, Haworth L, Sherry RM, Hwu P, Schwartzentruber DJ, Topalian SL, et al.: A randomized trial of bevacizumab, an anti-vascular endothelial growth factor antibody, for metastatic renal cancer. N Engl J Med. 2003; 349: 427-34.

19. Hudes G, Carducci M, Tomczak P, Dutcher J, Figlin R, Kapoor A, et al.: Temsirolimus, interferon alfa, or both for advanced renal-cell carcinoma. N Engl J Med. 2007; 356: 2271-81.

20. Pierorazio PM, McKiernan JM, McCann TR, Mohile S, Petrylak D, Benson MC: Outcome after cytoreductive nephrectomy for metastatic renal cell carcinoma is predicted by fractional percentage of tumour volume removed. BJU Int. 2007; 100: 755-9.

21. Motzer RJ, Bacik J, Murphy BA, Russo P, Mazumdar $\mathrm{M}$ : Interferon-alfa as a comparative treatment for clinical trials of new therapies against advanced renal cell carcinoma. J Clin Oncol. 2002; 20: 289-96.

22. Motzer RJ, Hutson TE, Tomczak P, Michaelson MD, Bukowski RM, Oudard S, et al.: Overall survival and updated results for sunitinib compared with interferon alfa in patients with metastatic renal cell carcinoma. $\mathrm{J}$ Clin Oncol. 2009; 27: 3584-90.

23. Kusmartsev S, Vieweg J: Enhancing the efficacy of cancer vaccines in urologic oncology: new directions. Nat Rev Urol. 2009; 6: 540-9.

Accepted after revision:

July 27, 2010

\section{Correspondence address:}

Dr. Marcos F. Dall'Oglio

Rua Barata Ribeiro, 398 / 50. Andar

Fax: + $55113159-3618$

São Paulo, SP, 01308-000, Brazil

E-mail: marcosdallogliouro@terra.com.br

\section{EDITORIAL COMMENT}

Renal cell carcinoma is frequently asymptomatic in its early stages. As a consequence, a high percentage of patients is diagnosed with metastatic disease at initial presentation. In advanced stages treatment results are extremely poor with an overall median survival of less than one year. Nephrectomy and/or systemic treatment with cytotoxic chemotherapy have poor or no effectiveness.

Recently, the use of molecular targeted therapies have shown survival benefits for patients with metastatic renal cell carcinoma. A new possibility is a consequence of the development of dendritic cells in vitro which are potent antigen-presenting cells. Some studies have shown significant response in metastatic disease using vaccines based on dendritic cells hybridized with cells from the tumor itself.

Dr. Dall'Oglio et al. report a novel initial experience with two patients treated with multi-modality approach combining a molecular targeted drug, cytoreductive nephrectomy, and hybrid dendritic cell 
vaccine. Follow-up of 9 and 10 months have demonstrated stable disease in both, as shown by imaging and clinical findings, with no further treatment required.

This is a very promising result. We hope that new trials with higher number of patients and longer follow-up confirm the benefit in the immune response obtained with dendritic cell vaccine combined with the antiangiogenic effect of sunitinib in the treatment of metastatic renal cell carcinoma.

Dr. Athanase Billis

Full-Professor of Pathology State University of Campinas, Unicamp Campinas, São Paulo, Brazil E-mail: athanase@fcm.unicamp.br

\section{EDITORIAL COMMENT}

Renal cell carcinoma (RCC) still is a major health problem and almost half of the patients have locally advanced or metastatic disease at the time of the diagnosis. Recently, targeting agents have demonstrated benefits in progression free-survival and overall survival in patients bearing a metastatic RCC. Currently, these drugs are recommended as first and second line standard of care in metastatic RCC (1). But despite proven efficacy, complete response is rarely seen. Therefore, new strategies and treatment modalities are required to optimize RCC outcomes.

Several therapeutic strategies are under investigation in urologic oncology. Urologists are familiar with immunotherapy, since these interventions have long been utilized for kidney (IL-2, IFN alfa) and bladder cancer (BCG) treatments. Theoretically, vaccinated patients could develop an immune surveillance, able to lead either to a postponed recurrence or prolonged cancer specific-survival. At present, therapeutic potential of vaccines against metastatic RCC is limited as highlighted by the authors. Nevertheless, metastatic RCC patients treated with DC vaccines showed promising results in several phase I/II trials (2). In an investigative scenario, considerable interest exists in simultaneous delivery antiangiogenic drugs and vaccines. The tumor immune-suppressive microenvironment could be a possible explanation to why tumors can evade the immune system. Tyrosine kinase inhibitors might sinergically contribute to restore the impaired tumormediated immune response and thereby improve vaccine efficacy.

In the present report, a word of caution must be emphasized to underline the major limitation of this combined antitumor strategy. Since both patients received sunitinib, we cannot confirm if the clinical response presented by these two patients was anyhow impacted by the concomitant use of DC vaccine. Certainly, this issue can only be addressed in a future phase 3 clinical trial.

\section{REFERENCES}

1. Ljungberg B, Cowan NC, Hanbury DC, Hora M, Kuczyk MA, Merseburger AS, et al.: EAU guidelines on renal cell carcinoma: the 2010 update. Eur Urol. 2010; 58: 398-406.

2. Van Poppel H, Joniau S, Van Gool SW: Vaccine therapy in patients with renal cell carcinoma. Eur Urol. 2009; 55: 1333-42.

\author{
Dr. Flavio L. Heldwein \\ Discipline of Urology \\ Univ. do Sul de Santa Catarina (UNISUL) \\ Florianopolis, SC, Brazil \\ E-mail:flavio.lobo@gmail.com
}

